\title{
Why acute kidney injury during partial nephrectomy matters
}

\author{
Carlo A. Bravi ${ }^{1,2}$, Andrew Vickers ${ }^{2}$ \\ ${ }^{1}$ Division of Oncology/Unit of Urology, URI, IRCCS Ospedale San Raffaele, Milan, Italy; ${ }^{2}$ Memorial Sloan Kettering Cancer Center, New York, \\ NY, USA \\ Correspondence to: Carlo A. Bravi, MD. Division of Oncology/Unit of Urology, URI, IRCCS Ospedale San Raffaele, Via Olgettina 60, Milan 20132, \\ Italy. Email: bravi.carloandrea@hsr.it. \\ Provenance: This is an invited article commissioned by the Section Editor Dr. Xiao Li (Department of Urology, Jiangsu Cancer Hospital, Jiangsu \\ Institute of Cancer Research, Nanjing Medical University Affiliated Cancer Hospital, Nanjing, China). \\ Response to: Kim WH, Yoon HK, Lee HJ. Acute kidney injury and long-term renal function after partial nephrectomy-is there a true association? \\ Ann Transl Med 2019;7:S241. \\ Kim CS, Bae EH, Ma SK, et al. Usefulness of the duration of acute kidney injury for predicting renal function recovery after partial nephrectomy. \\ Ann Transl Med 2019;7:S236. \\ Rosiello G, Capitanio U, Larcher A. Acute kidney injury after partial nephrectomy: transient or permanent kidney damage?-Impact on long-term \\ renal function. Ann Transl Med 2019. doi: 10.21037/atm.2019.09.156.
}

Submitted Dec 12, 2019. Accepted for publication Dec 18, 2019.

doi: $10.21037 /$ atm.2019.12.131

View this article at: http://dx.doi.org/10.21037/atm.2019.12.131

We thank our colleagues for their interest in our paper assessing the association between acute kidney injury (AKI) during partial nephrectomy and renal function 1 year after surgery (1).

We agree with Rosiello and colleagues that partial nephrectomy has an intrinsic risk of AKI $(2,3)$. It has been shown that approximately 1 in 5 patients are at risk of acute damage that may eventually result in chronic kidney disease $(1,4,5)$. Even for experienced surgeons, identification of patients at risk of acute damage is of paramount importance and can be done using a number of predictive tools available in the literature $(6,7)$. Moreover, we reiterate recommendations towards adequate postoperative management of these patients, including fluid resuscitation in case of volume depletion or avoiding nephrotoxic agents after surgery.

In addition, implementation of AKI criteria should be pursued, as suggested by Kim et al. (8). Several biomarkers have been proposed (9) which have the potential to improve stratification of patients before and after surgery. Awaiting future validations, we believe that the implementation provided by AKI duration has the clear advantage that the dimension of time is easy to calculate and does not necessitate additional data collection. When it comes to the optimal definition of AKI, Kim and colleagues (2) raised concerns about possible overestimation of AKI due to the lack of parenchymal mass reduction (10). As we elaborated elsewhere (11), our paper included sensitivity analyses using alternative criteria (12) which almost halved the incidence of AKI (11\% vs. 20\%), with no meaningful differences from our primary analyses. Accordingly, we are confident that our findings were not a consequence of overestimation of AKI.

Finally, Kim et al. (13) criticized the lack of long-term assessment of renal function, suggesting that the association between AKI and 1-year function might not hold true at longer follow-up. To test this hypothesis, they recommend the use of functional change ratio (FCR), defined as longterm estimated glomerular filtration rate (eGFR) (most recent value)/new baseline eGFR assessed 3 to 12 months after surgery (14). However, such construct deserves further consideration. In the original paper (14), while median creatinine 3 to 12 months after surgery was worse than median preoperative function $(1.51 \mathrm{vs} .1 .26 \mathrm{mg} / \mathrm{dL})$, it was not that much different from median long-term function (1.54 mg/dL, median follow-up: 45 months) (14). This suggests that patients treated with partial nephrectomy are at risk of functional deterioration up to 1 year after surgery, but renal function remains substantially stable thereafter. Under this assumption, findings from Zabell et al. (14) 
actually corroborate our results suggesting that renal function 1 year after surgery is adequate to evaluate whether AKI translates into long-term damage $(1,15)$.

In conclusion, our colleagues raised a number of interesting points. None have a substantive impact on our key finding that AKI is associated with renal function at 1 year, but they do provide insight to guide future research directions.

\section{Acknowledgments}

None.

\section{Footnote}

Conflicts of Interest: The authors have no conflicts of interest to declare.

Ethical Statement: The authors are accountable for all aspects of the work in ensuring that questions related to the accuracy or integrity of any part of the work are appropriately investigated and resolved.

\section{References}

1. Bravi CA, Vertosick E, Benfante N, et al. Impact of acute kidney injury and its duration on long-term renal function after partial nephrectomy. Eur Urol 2019;76:398-403.

2. Rosiello G, Capitanio U, Larcher A. Acute kidney injury after partial nephrectomy: transient or permanent kidney damage?-Impact on long-term renal function. Ann Transl Med 2019. doi: 10.21037/atm.2019.09.156.

3. Bravi CA, Larcher A, Capitanio U, et al. Perioperative outcomes of open, laparoscopic, and robotic partial nephrectomy: a prospective multicenter observational study (the RECORd 2 project). Eur Urol Focus 2019. [Epub ahead of print].

4. Chawla LS, Eggers PW, Star RA, et al. Acute kidney injury and chronic kidney disease as interconnected syndromes.

N Engl J Med 2014;371:58-66.

5. Bravi C, Capitanio U, Mari A, et al. Ischemia time during partial nephrectomy has a different impact on renal function loss according to preoperative risk of acute kidney injury. Results from a prospective multicenter observational study (the RECORD2 project). European
Urology Supplements 2019;18:e3317.

6. Martini A, Sfakianos JP, Paulucci DJ, et al. Predicting acute kidney injury after robot-assisted partial nephrectomy: Implications for patient selection and postoperative management. Urol Oncol 2019;37:445-51.

7. Bertolo R, Garisto J, Li J, et al. Development and internal validation of a nomogram for predicting renal function after partial nephrectomy. Eur Urol Oncol 2019;2:106-9.

8. Kim CS, Bae EH, Ma SK, et al. Usefulness of the duration of acute kidney injury for predicting renal function recovery after partial nephrectomy. Ann Transl Med 2019;7:S236.

9. Antonelli A, Allinovi M, Cocci A, et al. The predictive role of biomarkers for the detection of acute kidney injury after partial or radical nephrectomy: a systematic review of the literature. Eur Urol Focus 2020;6:344-53.

10. Zhang $Z$, Zhao J, Dong W, et al. Acute kidney injury after partial nephrectomy: role of parenchymal mass reduction and ischemia and impact on subsequent functional recovery. Eur Urol 2016;69:745-52.

11. Bravi CA. Reply to Won Ho Kim, Hyun-Kyu Yoon, Chang Wook Jeong's Letter to Editor re: Carlo Bravi, Emily Vertosick, Nicole Benfante, et al. Impact of acute kidney injury, its duration on long-term renal function after partial nephrectomy. Eur Urol 2019;76:398-403. Eur Urol 2020;77:e16-7.

12. Pickering JW, Endre ZH. GFR shot by RIFLE: errors in staging acute kidney injury. Lancet 2009;373:1318-9.

13. Kim WH, Yoon HK, Lee HJ. Acute kidney injury and long-term renal function after partial nephrectomy-is there a true association? Ann Transl Med 2019;7:S241.

14. Zabell J, Isharwal S, Dong W, et al. Acute kidney injury after partial nephrectomy of solitary kidneys: impact on long-term stability of renal function. J Urol 2018;200:1295-301.

15. Martini A, Cumarasamy S, Beksac AT, et al. A nomogram to predict significant estimated glomerular filtration rate reduction after robotic partial nephrectomy. Eur Urol 2018;74:833-9.

Cite this article as: Bravi CA, Vickers A. Why acute kidney injury during partial nephrectomy matters. Ann Transl Med 2020;8(4):134. doi: 10.21037/atm.2019.12.131 